\title{
Unmasking the hidden pandemic: sustainability in the setting of the COVID-19 pandemic
}

\author{
Arefeh Ahmadifard*1
}

\section{Key points}

Plastic consumption and waste have increased considerably as a direct consequence of the COVID-19 pandemic through increased PPE provisions in dental settings.
The increased use of plastic as a direct result of the dental profession's PPE provisions will contribute to environmental pollution. Therefore, we must invest into maximising its use at every stage of its life cycle.
Sustainable action and risk reduction approaches must form part of COVID-19 response and recovery strategies to avoid future environmental crises.

\begin{abstract}
The advent of the COVID-19 pandemic has seen disruptions to almost all aspects of society, and the environment will not be left unaffected. With increased personal protective equipment (PPE) provisions in dental settings, plastic consumption and disposal are likely to increase significantly. This poses the risk of an environmental crisis from increased pollution if the production and disposal of plastic-based PPE products are not managed effectively. Learning from natural disaster management approaches and past crises, we must align our short-term goals of responding to the COVID-19 pandemic with our long-term vision for environmentally conscious action. Sustainable activity will underpin a successful response to our current health crisis.
\end{abstract}

\section{Introduction}

At the start of this decade, if you were posed with the question of what the future will look like in six months, would your answer match the reality that we are living today? The answer would undoubtedly be no.

The COVID-19 pandemic has jolted us from routine life, with healthcare systems, educational sectors and global activities undergoing huge transformative change. Our environment is certainly no exception.

Extensive travel restrictions coupled with reductions in industrial activities have seen the environment reap huge benefits; there are numerous reports of improvements in air quality and reductions in carbon emissions and greenhouse gases. ${ }^{1,2}$ Yet, the flourishes in the environment should not overshadow a more pressing issue that poses the threat of an environmental crisis: plastic pollution.

${ }^{1}$ Barts and the London School of Medicine and Dentistry. Turner St, Whitechapel, London, E1 2AD, UK.

*Correspondence to: Arefeh Ahmadifard

Email address: a.ahmadifard@smd16.qmul.ac.uk

Refereed Paper.

Accepted 21 July 2020

https://doi.org/10.1038/s41415-020-2055-z

\section{Plastic: friend or foe?}

Plastic is a staple in the healthcare sector. The masks, gloves and gowns that form our personal protective equipment (PPE) all comprise of plastic in some form or another. In the wake of the pandemic, the NHS has seen an expanded workforce, encompassing re-joining healthcare staff and an increased volunteering effort. Combining this with the fact that the occurrence of protective equipment is no longer limited to medical settings, PPE provisions have increased significantly as a direct consequence of the COVID-19 pandemic.

The statistics confirm this; the WHO estimated that 89 million medical masks and 76 million examination gloves were required each month in the global response to the COVID-19 pandemic. $^{3}$ Although there have been widespread reports of PPE shortages, even if a fraction of those figures have been met, that is a substantial quantity of PPE circulated in use.

With many dental practices now reopening and operating under enhanced PPE provisions, our profession will undoubtedly contribute significantly to the dramatic rise in PPE production and use. The push for more robust forms of protection in dental settings can be explained by the physical aspects of our occupation; social distancing is unfeasible as dental teams are required to work in close proximity with patients and one another, a significant portion of procedures are aerosol generating procedures (AGPs) due to the use of high-speed drills or ultrasonic scalers, and the nature of the work means that we are likely to be exposed to bodily fluids such as saliva and blood. Taking into consideration that COVID-19 can be transmitted through respiratory droplets as well through contact, ${ }^{4}$ dental professionals are faced with an elevated risk of exposure to the virus. ${ }^{5}$ Consequently, to ensure that dental healthcare professionals are operating in safe work environments and to reduce transmission of the virus, enhanced PPE provisions are being introduced.

Thus, dentistry is currently navigating a new normality for protective equipment. Where previously our universal precaution warranted only the use of basic PPE, current government guidance outlines that healthcare workers involved in AGPs are required to wear a long-sleeved disposable gown, gloves and eye protection consisting of either a full-face visor or disposable goggles and a respirator, while non-AGPs will require 
fluid-repellent face masks, aprons, gloves and eye protection, all of which will comprise of plastic in some form. ${ }^{6}$ However, despite the increases in PPE provisions, there have been no such increases in the capacity to deal with the increased demand or resulting clinical waste sustainably.

Our profession's increased use of PPE is problematic in two regards: its production and disposal. Considering the former, increased PPE provisions will fuel plastic production, which will in turn increase sourcing through practices such as fracking or petrochemical manufacturing, processes which are notoriously harmful to the environment and substantial contributors to carbon pollution. ${ }^{7}$

With regards to its disposal, PPE is classified as clinical waste and, as such, its disposal may involve incineration, the process of which emits air pollutants and toxins. ${ }^{8}$ Research highlights that plastic is unlikely to be completely eliminated through burning and often leaves residues of nano- and micro-sized plastic particles, which are harmful both to the atmosphere and to the ecosystems they are introduced into. ${ }^{8}$ Increased PPE provisions in dentistry will lead to increased production of clinical waste, which will ultimately lead to an increase in the amount of plasticbased products that are being incinerated. Therefore, as a direct consequence of the pandemic and our use of PPE, the dental profession's contribution to pollution will have greatly increased. However, the impacts of the pandemic on plastic consumption reach beyond a population level, extending to policy.

Prior to the lockdown, awareness on sustainability had gathered great momentum and the legislation reflected this - the Paris Agreement (2016) and the Sustainable Development Goals (2015) outlined by the United Nationals General Assembly were a promise of global commitment to combat climate change. ${ }^{9}$

With the abundance of single-use plastics in practices, our profession contributed considerably to the environmental burden associated with air and plastic pollution. However, as awareness grew, many pledged to combat ecologically harmful practices and to work towards a more sustainable landscape for healthcare to operate in. ${ }^{10}$

Understandably, the focus of many governing bodies, dental practices and institutions have now shifted from environmental protection to deal with our immediate health crisis. As such, policy changes have been hindered through the postponement of key events, such as the United Nations Climate Change Conference. ${ }^{11}$ Additionally, economic disruptions may mean that many practices will face significant financial barriers in investing into sustainable practices. Therefore, attitude shifts as a result of the pandemic may delay environmentally conscious action and reform in the dental profession.

\section{Circular economy}

The concept of circular economy is often raised in conversations concerning sustainability. At its core it describes how, through careful design, pollution and detriments to the environment associated with the consumption of a material can be reduced by maximising its utility at all stages of its life cycle. This includes its production and waste management. ${ }^{12}$ Therefore, applying this principle in a dental context, if we were to use plastic sustainably, we must not only try to reduce our plastic consumption as part of our PPE provisions, but also maximise its management.

In line with this, one approach in managing PPE disposal sustainably would be to improve current waste management infrastructures and develop systems that allow PPE to be recycled, reused and processed, with minimal resulting damage to the environment. However, in the setting of the COVID-19 pandemic, we are presented with a unique set of problems. Masks imported from China are reported to comprise of a combination of polymers and materials, which may make their separation very complex. ${ }^{13}$ The issue is compounded further by reports that COVID-19 persists on plastic surfaces for 2-3 days. ${ }^{14}$ This means that the contamination of any medical protective equipment may complicate reuse or recycling.

Perhaps the most substantial way in which we could achieve a reduction in our use of plasticbased PPE would be to invest in alternative, more renewable materials. This is a sentiment that has been reflected in the manufacturing sector. In the hopes of providing more sustainable options for protective equipment in the setting of the pandemic, plastic-free visors comprising of sustainably sourced wood pulp and paper have been launched in the UK. ${ }^{15}$ These products seem to be of a comparable quality to their plastic-based counterparts, evidenced by their CE certification by the European Economic Area (EEA).

Not only are the materials and the sourcing processes of these visors sustainable, but so is their waste management; rather than being processed through incineration, these products can be disposed of with organic waste and degrade as compost. Reports from existing literature and the US Composting Council highlight that composting has been shown to be an effective disposal method for virally infected animal carcasses, as the time and high temperature associated with compost cycles degrade viral RNA. ${ }^{16,17}$ This may address concerns that this mode of disposal could contribute to the transmission of COVID-19.

Thus, these materials seem to be an attractive alternative, helping to reduce the negative environmental impacts associated with procuring, processing and disposing of plasticbased products. However, considerations must also be made for the barriers that must be overcome if we are to adopt such products and materials into our practices and PPE. Firstly, while CE-certified, we must consider the suitability of such materials in dental settings and their performance in exposure to splatter and aerosols. Secondly, the production capacity of these manufacturers may not be large enough to meet the needs of the dental sector in the UK and may consequently limit access. Thirdly, countless dental practices are suffering financially as a consequence of the pandemic and do not have the ability nor the financial incentives to invest into sustainable equipment and practices at present. Finally, we must consider additional provisions that would be necessary, such as industrial-scale composting sites in order to provide the right conditions for the breakdown of these products. However, despite these limitations, the principle still stands that alternative materials exist and have the potential to be incorporated into the profession and our practices.

While many questions are raised about sustainable practices, it is essential to clarify that the safety of our population and key workers should always be a priority. There is no doubt that their welfare and best interests should always be safeguarded. Evidently, plastic seems indispensable in achieving this.

The real question to consider here is: can we align our short-term goals of responding to this pandemic with our long-term vision for environmentally conscious action? Sustainable practices and an effective and successful response to the COVID-19 pandemic do not have to be mutually exclusive. In fact, I argue that sustainable practice determines whether our response to the COVID-19 pandemic is effective. 


\section{Learning from natural disaster management approaches}

When natural disaster strikes, the action of communities and governing bodies can be grouped into two categories: response and recovery. The former encompasses activities that address short-term needs in a timely manner, while the latter focuses on the longterm rehabilitation of the affected society. ${ }^{18}$ For instance, when an earthquake hit near Christchurch, New Zealand in 2011, in addition to emergency medical and housing provisions, response organisations also funded projects aimed at restoring infrastructure and strengthening long-term psychosocial recovery. ${ }^{18}$ This is evidence that pragmatic approaches that balance short-term needs with long-term goals are realistic and achievable.

The COVID-19 pandemic could be likened to a natural disaster in that it has resulted in significant loss of life and disruptions to routine activity. Just as parallels can be drawn between their impacts, parallels should also be drawn in our responses in both of these situations. If the management following an earthquake would not solely focus on investing in immediate provisions such as food, our actions in light of the pandemic cannot focus on the immediate crisis alone. Therefore, we must consider how we can mitigate the damage of future environmental crisis and develop effective risk reduction strategies.

It is also important to emphasise that this pandemic is not the problem. Its occurrence lends a spotlight to illuminate the real issue - our response to crisis. Historically, sustainability and environmental quality have not been prioritised in the face of adversity. Following the financial crisis of 2008, despite initially observing a reduction, carbon emissions saw record-breaking peaks in 2010 and delays in climate action policies. ${ }^{19,20}$ Is it possible that we could observe a similar pattern with the COVID-19 pandemic?

We may be treading in unprecedented waters, but this is far from the first health crisis we have faced - severe acute respiratory syndrome (SARS), polio, influenza and Ebola all highlight that our population is always at threat from a new crisis or disease. Taking into consideration that the COVID-19 pandemic is reported to persist for some time $e^{21}$ and that it likely will not be the last public health crisis we face, it is now more than ever imperative that we involve the topic of sustainability into our discussions and PPE provisions.

Following the SARS outbreak of 2002-2004, research highlighted that increased fatality from SARS-CoV-1 was linked to increased air pollution..$^{22}$ If COVID-19 behaves in a similar way, aiming to reduce air pollution now from our PPE consumption and disposal will form part of an effective, prophylactic public health measure.

Understandably, in the height of this pandemic, the dental profession will struggle to make sustainability a priority as we devote finances, resources and time to overcome the tremendous challenges currently posed by widespread PPE shortages and financial hardship. However, just as we transition through different stages of action in response to the pandemic, our conversations should also transition to include the topic of sustainability as soon as practically and financially feasible.

As a profession, we must drive the innovation of sustainable materials for PPE before a crisis. Only then can we ensure that we are well equipped in the face of adversity and that our provisions will not fuel a future environmental pandemic.

\section{Conclusion}

Plastic is a valuable commodity, especially in the setting of the COVID-19 pandemic. It seems to be indispensable in times of crisis, with its applications in PPE helping to protect dental healthcare professionals and the population. However, its use and abuse brings with it many issues that will affect planetary health. As such, we are presented with the twin challenge of responding effectively to the COVID-19 pandemic and also ensuring that our response is sustainable. If we are to continue without reform, our actions could trigger a public crisis in the future, putting the health of our environment at risk. As adversity paves the way for innovation, we are presented with an opportunity to impart substantial change and reform in our PPE provisions. Now, I pose to you the question: what will our future look like in six months, six years, or sixty years' time?

\section{References}

1. Muhammad S, Long X, Salman M. COVID-19 pandemic and environmental pollution: A blessing in disguise? $\mathrm{SC}$ Total Environ 2020; DOI: 10.1016/j.scitotenv.2020.138820.

2. Carbon Brief. Analysis: Coronavirus temporarily reduced China's $\mathrm{CO} 2$ emissions by a quarter. 2020. Available at https://www.carbonbrief.org/analysis-coronavirus-hastemporarily-reduced-chinas-co2-emissions-by-a-quarter (accessed June 2020).

3. World Health Organisation. Shortage of personal protective equipment endangering health workers worldwide. 2020. Available at https://www.who.int/ news-room/detail/03-03-2020-shortage-of-personalprotective-equipment-endangering-health-workersworldwide (accessed June 2020).
4. Public Health England. Transmission characteristics and principles of infection prevention and control. 2020. Available at https://www.gov. uk/government/publications/wuhan-novelcoronavirus-infection-prevention-and-control/ transmission-characteristics-and-principles-of-infectionprevention-and-control\#: :text=The\%20transmission $\% 20$ of $\% 20$ COVID $\% 2$ D, be $\% 20$ droplet $\% 20$ and $\% 20$ contact (accessed July 2020).

5. Gamio L, The New York Times. The Workers Who Face the Greatest Coronavirus Risk. 2020. Available online at https://www.nytimes.com/interactive/2020/03/15/ business/economy/coronavirus-worker-risk.html (accessed July 2020).

6. Public Health England. COVID-19: Infection Prevention and Control (IPC). 2020. Available online at https://www.gov. uk/government/publications/wuhan-novel-coronavirusinfection-prevention-and-control (accessed July 2020).

7. Forbes. Fives Ways That Plastics Harm The Environment (And One Way They May Help). 2018. Available at https:// www.forbes.com/sites/grrlscientist/2018/04/23/fiveways-that-plastics-harm-the-environment-and-one-waythey-may-help/\#600b666967a0 (accessed July 2020).

8. The Economist. Covid-19 has led to a pandemic of plastic pollution. 2020. Available at https://www.economist. com/international/2020/06/22/covid-19-has-led-to-apandemic-of-plastic-pollution (accessed July 2020)

9. Dzebo A, Janetschek H, Brandi C, lacobuta G. Connections between the Paris Agreement and the 2030 Agenda: The case for policy coherence. 2019. Available at https:// www.sei.org/wp-content/uploads/2019/08/connectionsbetween-the-paris-agreement-and-the-2030-agenda.pdf (accessed August 2020).

10. British Dental Association. Sustainability in Dentistry. 2020. Available at https://bda.org/about-the-bda/ campaigns/sustainable/Pages/Sustainability-in-dentistry. aspx (accessed June 2020)

11. United National Climate Change Conference UK 2020. COP26 postponement. 2020. Available at https://www. ukcop26.org/cop26-postponement/ (accessed June 2020).

12. Geissdoerfer M, Savaget P, Bocken N, Hultink E J. The Circular Economy - A New Sustainability Paradigm? J Clean Prod 2017: 143: 757-768.

13. Monella $L \mathrm{M}$. Will plastic pollution get worse after the COVID-19 pandemic? Euronews (France) 2020 May 13. Available at https://www.euronews.com/2020/05/12/ will-plastic-pollution-get-worse-after-the-covid-19pandemic (accessed June 2020).

14. van Doremalen N, Bushmaker T, Morris D H et al. Aerosol and Surface Stability of SARSCOV2 as Compared with SARSCoV1. N Engl J Med 2020; 382: 1564-1567.

15. Waste 360. Reelbrands Announces Plastic-Free, Compostable PPE Visor. 2020. Available at https://www. waste $360 . c o m / s u s t a i n a b i l i t y / r e e l b r a n d s-a n n o u n c e s-$ plastic-free-compostable-ppe-visor (accessed July 2020).

16. US Composting Council. Composting in the Time of COVID-19. 2020. Available online at https://www. composting council.org/page/Composting-In-The-Time-ofCOVID-19\#webinar1 (accessed July 2020).

17. Vitosh-Sillman S, Loy J D, Brodersen B, Kelling C, Eskridge $\mathrm{K}$, Millmier Schmidt A. Effectiveness of composting as a biosecure disposal method for porcine epidemic diarrhoea virus (PEDV)-infected pig carcasses. Porcine Health Manag 2017; 3: 22

18. Finucane M L, Acosta J, Wicker A, Whipkey K. ShortTerm Solutions to a Long-Term Challenge: Rethinking Disaster Recovery Planning to Reduce Vulnerabilities and Inequities. Int J Environ Res Public Health 2020; 17: 482.

19. Henriques M. Will Covid-19 have a lasting impact on the environment? 2020. Available at https://www.bbc com/future/article/20200326-covid-19-the-impact-ofcoronavirus-on-the-environment (accessed June 2020).

20. Financial Times. Pandemic sets back fight against singleuse plastic. 2020. Available online at https://www.ft.com/ content/c479a718-36a6-48e2-8632-a77290fc223a (accessed June 2020).

21. Centre for Infectious Disease Research and Policy. COVID19: The CIDRAP Viewpoint. 2020. Available online at https://www.cidrap.umn.edu/covid-19/covid-19-cidrapviewpoint (accessed August 2020).

22. Cui $Y$, Zhang Z F, Froines J et al. Air pollution and case fatality of SARS in the People's Republic of China: an ecologic study. Environ Health 2003; 2: 15. 